\title{
To compare the efficacy of drotaverine hydrochloride with hyoscine butylbroumide for increasing the rate of cervical dilatation
}

\author{
Uzma Kausar $^{1 *}$, Nikhat Siddiqui ${ }^{2}$
}

\author{
${ }^{1}$ Department of Obstetrics and Gynecology, MRA Medical College, Ambedkarnagar, Uttar Pradesh, India \\ ${ }^{2}$ Department of Obstetrics and Gynecology, Era's Lucknow Medical College, Lucknow, Uttar Pradesh, India
}

Received: 24 January 2017

Accepted: 02 March 2017

\author{
*Correspondence: \\ Dr. Uzma Kausar, \\ E-mail: njmsonline@gmail.com
}

Copyright: ( $)$ the author(s), publisher and licensee Medip Academy. This is an open-access article distributed under the terms of the Creative Commons Attribution Non-Commercial License, which permits unrestricted non-commercial use, distribution, and reproduction in any medium, provided the original work is properly cited.

\begin{abstract}
Background: In order to accelerate the labour apart from early amniotomy and early administration of oxytocin, the use of antispasmodic agents like drotaverine and hyoscine butylbromide to hasten the first stage of labor is a common practice. Considering the promising results of hyoscine butylbromide, the present study was planned to to compare the efficacy of drotaverine hydrochloride with hyoscine butylbroumide for increasing the rate of cervical dilatation.

Methods: This prospective placebo-controlled crossover study was carried out at Department of Obstetrics and Gynaecology, Era's Lucknow Medical College, Lucknow. The study was conducted on 60 women in labour who were randomly allocated to group I, group II and group III of 20 patients each. In group I, no intervention was done and comprised the control group. The women in group II were injected intramuscularly one ampoule (20mg) of hyoscine butylbromide. The women in Group III were injected Inj. Drotavrine one ampoule $(40 \mathrm{mg})$ intramuscularly at $3 \mathrm{~cm}$ dilatation. The data collected was analysed using SPSS Version 15.0. Suitable statistical tests were applied.

Results: Majority of subjects were aged between 21-30 years, were multipara and had spontaneous labour. Mean duration of first stage of labour ranged from 3 hoour 34 minutes (drotaverine hydrochloride) to 5 hour 45 minutes (control group) showing a significant intergroup difference. Mean total duration of labour ranged from $4 \mathrm{hr} 11 \mathrm{minutes}$ (drotaverine hydrochloride and hyoscine butylbromide groups) to $6 \mathrm{hr} 26$ minutes (control group) showing a significant intergroup difference ( $\mathrm{p}<0.001$ ). Majority of deliveries were full term normal deliveries.

Conclusions: Both drotaverine hydrochloride and hyoscine butylbromide could effectively reduce first stage as well as total duration of labour. Further studies are recommended to establish the comparative efficacy in terms of a side effect profile and relatively efficacy in view of various clinico-demographic variables.
\end{abstract}

Keywords: Drotaverine hydrochloride, Hyoscine butylbromide, Labour

\section{INTRODUCTION}

Prolonged labor often ends up in a great suffering for the parturient because of dehydration, confusion and infection. The foetus is exposed to a higher risk of infection and asphyxia. Inhibitory impulses in the form of spasm often impair the dilatation of cervix and prolong the duration of labour. ${ }^{1}$ O'Driscoll at the National Maternity Hospital, Dublin, introduced the concept of active management of labour and this has influenced obstetricians to change their outlook regarding the management of first stage of labour. ${ }^{2}$ Active management of labour is associated with a low incidence of prolonged labour and low cesarean section rate. ${ }^{3}$ Protraction of the first stage of labour, one of the components of prolonged labour, does not necessarily result in less than optimal uterine contractility. Its cause is multifactorial and cervix dilatation is the end result of these factors. Although methods to increase uterine 
contractility such as amniotomy and use of oxytocics have been shown to accelerate cervical dilatation, yet these methods are not without complications. ${ }^{4}$ Spasmolytics and spasmoanalgesics mixtures are administered to facilitate dilatation of the cervix during delivery and to shorten first stage of labour. ${ }^{5}$ An ideal antispasmodic for accelerations of cervical dilatations should have a prompt and long lasting action, no adverse effects on uterine contractility and be free from risk of uterine inertia. It should also have minimal side effects in the mother and foetus. ${ }^{6}$

Thus in order to accelerate the labour apart from early amniotomy and early administration of oxytocin, the use of antispasmodic agents like drotaverine, hyoscine butylbromide, dicyclomine valethamide bromide etc. to hasten the first stage of labor is a common practice. While valethamide and drotaverine have been the subject of a number of studies, there are limited reports comparing hyoscine butylbromide. ${ }^{7}$

Hyoscine butylbromide acts by inhibiting cholinergic transmission in the abdominal and pelvic parasympathetic ganglia, thus relieving spasm in the smooth muscles of gastrointestinal, biliary, urinary tract and in female genital organs, especially the cervico-uterine plexus and thus aiding cervical dilatation. Uterine contractions are not affected rather due to better co-ordination between uterine contractions and cervical dilatation, the latter is increased. It is barely absorbed and detectable in the blood and does not penetrate the blood-brain barrier and is therefore, generally well tolerated. ${ }^{8}$

Drotaverine hydrochloride is a highly potent antispasmodic agent acting on the smooth muscle but is devoid of anticholinergic effects as it acts through inhibitory effects on phosphodiesterase enzyme mainly phosphodiesterase enzyme IV. Near term human myometrium contains a higher proportion of rolipram sensitive type IV phosphodiesterase enzyme isoforms. Drotaverine inhibits them and causing smooth muscle relaxation. It does not cross the placenta and hence has no side effects on the fetus.

Considering the promising results of hyoscine butylbromide, the present study was planned to evaluate its efficacy against drotaverine hydrochloride in our setup.

\section{METHODS}

The present prospective placebo-controlled crossover study was carried out at Department of Obstetrics and Gynaecology, Era’s Lucknow Medical College, Lucknow, India after taking permission from institutional ethical committee. Study population comprised of all pregnant women undergoing labour those coming to Gynaecological OPD. Informed consent was obtained from all individuals. This was a two year interventional study starting from January 2010 to December 2011. Random sampling technique was used. Based on the findings of Tehalia et al, the sample size was calculated by the formula: $\mathrm{n}=\left(\mathrm{Z}_{\alpha}+\mathrm{Z}_{\beta}\right)^{2}\left(\sigma_{1}^{2}+\sigma_{2}^{2}\right) / \mathrm{d}^{2}, \alpha$ (level of significance) $=5 \%$ and $\beta$ (type II error) $=10 \%$, Power of test $=90 \%,\left(\sigma_{1}=13.2, \sigma_{2}=63.6, d=63.6\right)$. Thus sample size came out to be $n=20$ per group. ${ }^{7}$

All pregnant women at 3-4 cm dilatation, at 37-41 weeks, with vertex presentation and no contraindication for vaginal delivery were included. All females with preterm labour, previous caesarean section, twin pregnancy, APH, history of cervical encirclage and malpresentation were excluded.

The study was conducted on 60 women in labour who were randomly allocated to group I, group II and group III. Each group had 20 patients. In Group I, no intervention was done this comprised the control group. The women in group II were injected intramuscularly one ampoule (20 $\mathrm{mg}$ ) of hyoscine butylbromide. The women in Group III were injected Inj. Drotavrine one ampoule (40mg) intramuscularly at $3 \mathrm{~cm}$ dilatation. The women in group $\mathrm{C}$ served as control.

Latent phase of labour was accepted as upto $3 \mathrm{~cm}$ dilatation. No intervention was done till the patient reached $3 \mathrm{~cm}$ dilatation. After this time interval, oxytocin infusion was started at a rate of $6 \mu \mathrm{g} / \mathrm{ml}$ and titrated according to the uterine contractions. Artificial rupture of membranes was done under antibiotic cover at $4-5 \mathrm{~cm}$ dilatation along with an intra-muscular injection of either of the two drugs being tested. A second dose of the antispasmodic was not allowed for the course of the study. Cervical assessment was performed every two hours or earlier if otherwise indicated.

The following parameters were recorded: Time from admission to $3 \mathrm{~cm}$ dilatation, time at which Injection of antispasmodic was injected, time at which full dilatation of the cervix was achieved, total duration of first stage of labour, duration of second and third stages of labour and amount of bleeding in the third stage of labour.

Apart from these the pulse rate of the patient under labour was monitored hourly and every at 30 minutes after injection of the antispasmodic. Continuous fetal heart rate monitoring for high risk and intermittent monitoring at 15 minutes was also done in each patient. All the data was recorded in a record form.

\section{Statistical analysis}

The data collected was analysed using Statistical Package for Social Sciences (SPSS) Version 15.0. The following formulae were used for the purpose of analysis. Mean and standard deviation was calculated. Chi square test, analysis of variance (ANOVA) and Student 't' test was applied. $p$ values $<0.05$ was significant and $\mathrm{p}<0.001$ was considered very highly significant.

\section{RESULTS}


The total 60 patients enrolled were randomly allocated into three groups - group I comprised the control group and included 20 patients $(33.3 \%)$ in whom no intervention was done. In group II, there were 20 patients $(33.3 \%)$ in whom one ampoule Inj. hyoscine butylbromide was injected intramuscularly while in Group III, there were 20 patients $(33.3 \%)$ in whom one ampoule Inj. Drotavrine hydrochloride was administered intramuscularly.

Majority of subjects in all the three groups were aged between 21-30 years. There were $2(10 \%)$ subjects in Group I, 1 (5\%) in Group II and $3(15 \%)$ in group III who were aged $\leq 20$ years. Mean age of patients in Group I was $25.75 \pm 5.35$ years, in group II, it was $24.90 \pm 3.66$ years and in group III the mean age of patients was $24.95 \pm 4.35$ years. Statistically, there was no significant difference in age of patients in different groups (Figure 1).

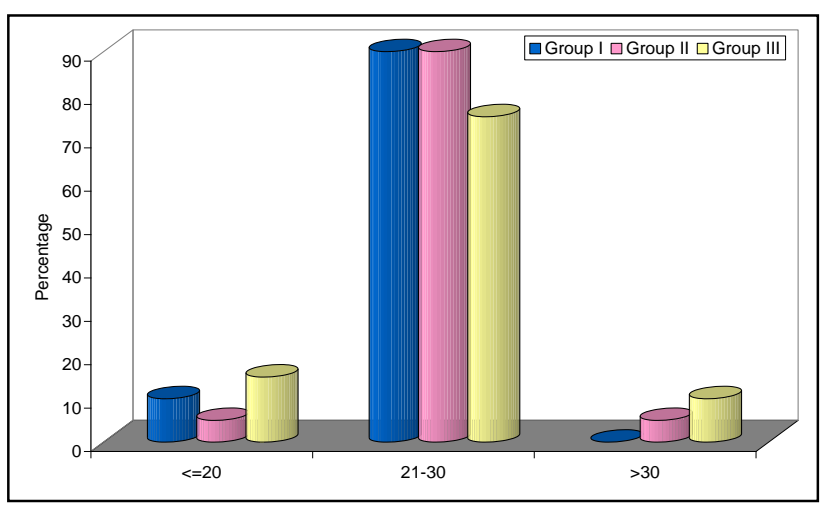

Figure 1: Distribution of subjects according to age groups.

The proportion of primipara subjects in Group I and Group III was $45 \%$, in Group II, this proportion was $40 \%$. Majority of subjects in all the three groups were multipara. Statistically, there was no difference among groups and the groups were matched $(\mathrm{p}=0.934)$ (Figure 2$)$.

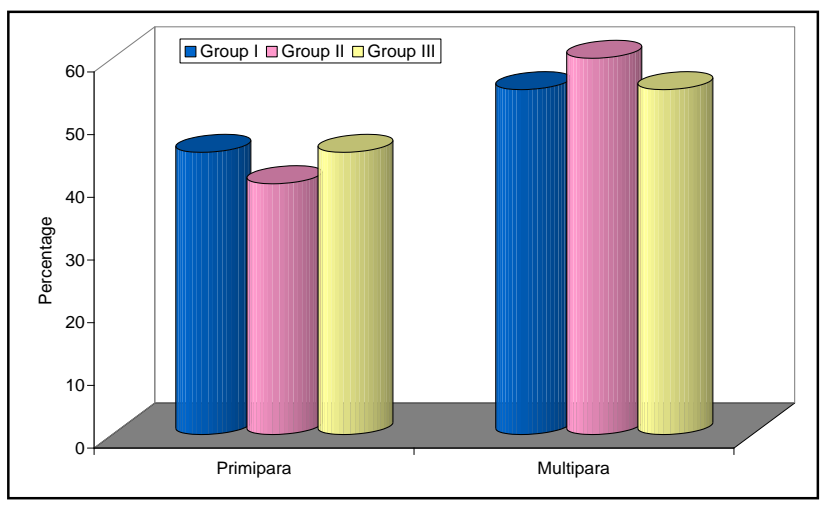

Figure 2: Distribution of subjects according to parity.

Distribution of subjects in two groups according to initial cervical dilatation showed that majority of subjects in all the three groups had initial cervical dilatation of $3 \mathrm{~cm}$. There were $5(25 \%)$ cases in Group I who had a cervical dilatation of $4 \mathrm{~cm}$ whereas in Group II $1(5 \%)$ subject had cervical dilatation of $3.5 \mathrm{~cm}$ and $3(15 \%)$ subjects had cervical dilatation of $4 \mathrm{~cm}$. In Group III, 3 (15\%) subjects had cervical dilatation of $4 \mathrm{~cm}$. Statistically, there was no significant difference among groups $(\mathrm{p}=0.583)$ (Figure 3$)$.

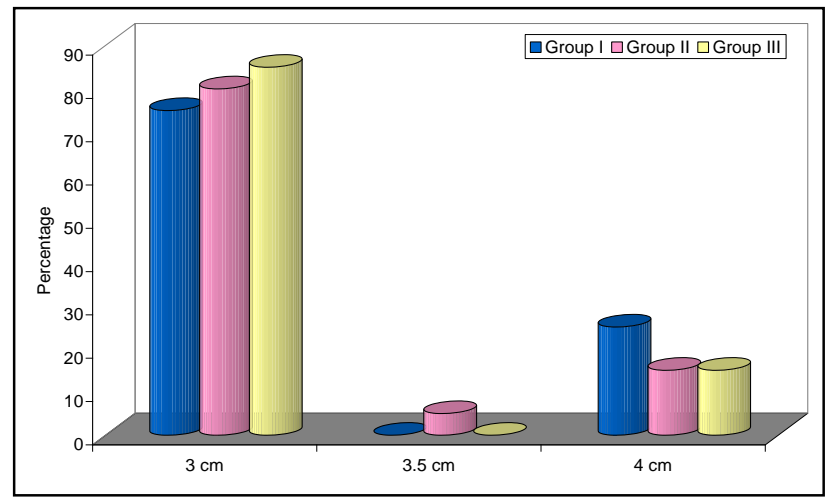

Figure 3: Distribution of subjects according to cervical dilatation.

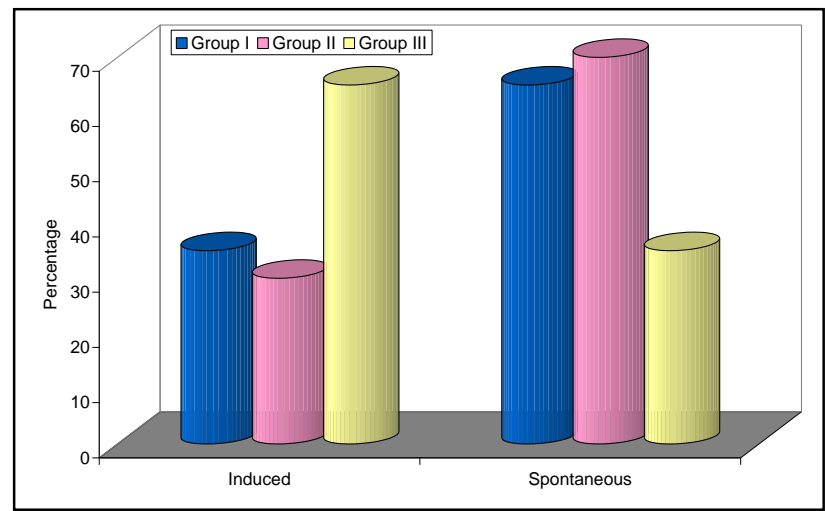

Figure 4: Distribution of subjects according to type of labour.

Majority of subjects in Groups I and II had spontaneous labour whereas majority of subjects in Group III had an induced labour. However, statistically, this difference among groups was significant $(\mathrm{p}=0.054)$ (Figure 4). As compared to Group I both groups II and III took lower time for all the three stages of labour. However, intergroup difference was significant only for Stage I ( $\mathrm{F}=18.741$; $\mathrm{p}$ $<0.001)$. A significant difference among groups was observed in total duration of labour too $(\mathrm{p}<0.001)$ (Table $1)$.

As compared to Group I both groups II and III took lower time for all the three stages of labour. However, intergroup difference was significant only for Stage I $(\mathrm{F}=18.741$; $\mathrm{p}$ $<0.001)$. A significant difference among groups was observed in total duration of labour too $(\mathrm{p}<0.001)$ (Table $1)$. 
Table 1: Duration of different stages of labour in three groups.

\begin{tabular}{|lllllllll|}
\hline \multirow{2}{*}{ Stage } & Group I $(\mathbf{n}=\mathbf{2 0})$ & \multicolumn{2}{l|}{ Group II $(\mathbf{n = 2 0})$} & \multicolumn{2}{l|}{ Group III $(\mathbf{n = 2 0})$} & \multicolumn{2}{l|}{ Significance of difference (ANOVA) } \\
& Mean & SD & Mean & SD & Mean & SD & F & p \\
\hline I (hr:min) & $5: 45$ & $1: 16$ & $3: 40$ & $1: 14$ & $3: 34$ & $1: 09$ & 18.741 & $<0.001$ \\
\hline II (min) & 36.11 & 23.55 & 24.00 & 10.08 & 27.25 & 11.97 & 2.872 & 0.065 \\
\hline III (min) & 7.78 & 3.42 & 6.60 & 2.33 & 6.25 & 2.61 & 1.525 & 0.227 \\
\hline Total & $6: 26$ & $1: 25$ & $4: 11$ & $1: 13$ & $4: 11$ & $1: 16$ & 18.697 & $<0.001$ \\
\hline
\end{tabular}

Table 2: Between group differences for time taken for different stages of labour.

\begin{tabular}{|llllllllll|}
\hline \multirow{2}{*}{ Stage } & Group I vs Group II & \multicolumn{3}{c|}{ Group I vs Group III } & \multicolumn{2}{c|}{ Group II vs Group III } \\
& MD & SE & "p" & MD & SE & "p" & MD & SE & "p" \\
\hline I (hr:min) & $2: 04$ & $0: 23$ & $<0.001$ & $2: 10$ & $0: 24$ & $<0.001$ & $0: 06$ & $0: 23$ & 0.964 \\
\hline II (min) & 12.11 & 5.19 & 0.060 & 8.86 & 5.19 & 0.213 & -3.25 & 5.06 & 0.797 \\
\hline III (min) & 1.18 & 0.91 & 0.405 & 1.53 & 0.91 & 0.223 & 0.35 & 0.87 & 0.918 \\
\hline Total & $2: 15$ & $0: 25$ & $<0.001$ & $2: 15$ & $0: 25$ & $<0.001$ & $0: 00$ & $0: 24$ & 1.000 \\
\hline
\end{tabular}

For stage I as well as for total duration, between Group comparisons revealed that both Groups II and III took significantly shorter time as compared to Group I $(\mathrm{p}<0.001)$. However, no significant difference was observed between Group II and III ( $\mathrm{p}=0.964)$ (Table 2). Between group comparisons for Stage II and Stage III did not show a statistically significant intergroup difference for any of the comparisons ( $p>0.05)$.

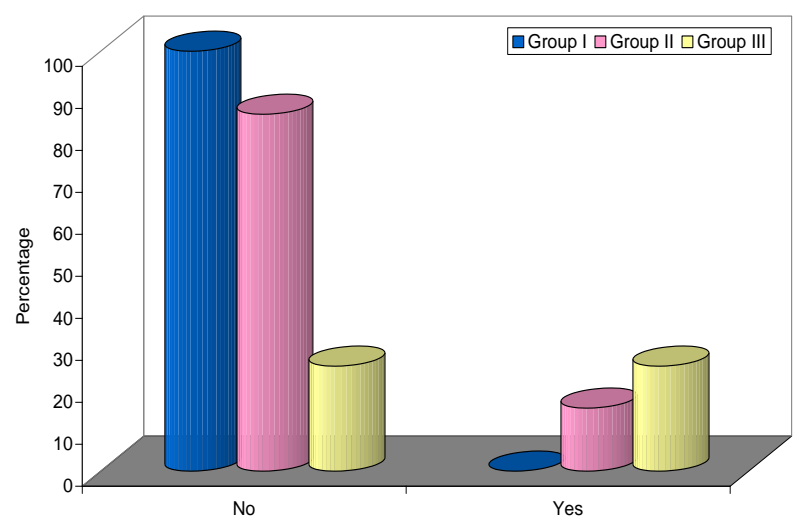

Figure 5: Distribution of subjects according to side effects.

Side effects like nausea, FT, MT or FB were observed in 3 (15\%) of Group II and 5 (25\%) of Group III subjects. On comparing the data statistically, no significant intergroup difference was observed $(\mathrm{p}=0.065)$ (Figure 5).

Majority of subjects had full term normal delivery. There were $6(30 \%)$ subjects in Group I, $1(5 \%)$ in Group II and $2(10 \%)$ in Group III who delivered through caesarean section. There was 1 subject in Group III who had an instrumented delivery. On comparing the data statistically this difference was not found to be significant $(\mathrm{p}=0.064)$ (Figure 6).

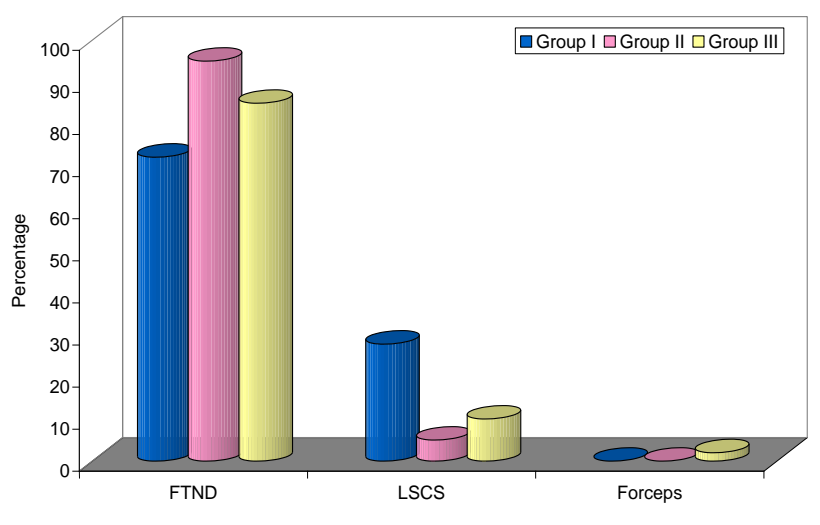

Figure 6: Distribution of subjects according to type of delivery.

\section{DISCUSSION}

Labour pain is among the most severe pain experienced by women. It is not simply the physical pain that can be explained on basis of physiological, chemical and neurological phenomena but it is aggravated by anxiety, fear and ignorance. The process of labour puts great strain on the mother and her fetus. Acceleration of labour to shorten its duration without adverse events for mother and fetus condition would therefore minimize the maternal and fetal morbidity and mortality. ${ }^{9}$

Inactive management of labour along with good uterine contraction simultaneous cervical dilatation and softening are required. But in spite of good uterine contractions, the cervical dilatation may be hampered due to inhibitory impulse in the form of spasm. In such cases antispasmodics help in the dilatation of cervix. A number of drugs have been used with an aim to shorten the duration of labour in general and that of first stage of labour in particular with the minimum possible or almost no side effects. Sedatives and belladonna Alkaloids have been 
tried to hasten cervical dilatation but many have adverse effects on mother and fetus. ${ }^{10}$ Although methods to increase uterine contractility such as amniotomy and use of oxytocics have been used to accelerate cervical dilation, yet these methods are not without complications. ${ }^{11}$ The use of antispasmodic agents like Drotaverine hydrochloride, hyoscinebutyl bromide, dicyclomine valethamide bromide etc. to hasten the first stage of labour is a common practice. While valethamide and drotaverine have been the subject of a number of studies, there are limited reports comparing hyoscine butylbromide. ${ }^{7}$

Drotaverine hydrochloride is a highly potent antispasmodic agent which acts on the smooth muscle and is devoid of anticholinergic effects thus it is a promising and rather better alternative to hasten the first stage of labour. However, the only drawback is that there are limited studies that have been conducted to evaluate it against the commonly used antispasmodic drugs like hyoscine butylbromide. In present study we have made an attempt to evaluate the efficacy of Drotaverine hydrochloride against hyoscine butylbromide. The efficacy of both the drugs was also tested against a nointervention group i.e. control group.

Age of subjects ranged from 18-35 years in this study. In different series the age of pregnant women has been also quoted between 18-35 years. ${ }^{12-14}$ The reason for this relatively long range of age in our series might be because we have included both primi and multipara women in our series whereas most of the studies have limited their scope to primipara women only. In present study, majority of women were multiparous. In present study, majority of women were multiparous. In literature, researchers have carried out most of the studies among primiparous women. ${ }^{25,26}$ Some studies have been carried out in both primipara and multipara women. ${ }^{7,15-17}$

Most of the studies in literature have sought to explore the relationship among primipara women for the reason that in primipara the first stage of labour is complex while in multipara owing to experience of previous delivery the first stage is much relaxed. However, in present study we have included both primi and multipara women so as to assess the efficacy of both the drugs irrespective of parity. Ours was a comparative study of two drugs and inclusion of either primi or multipara women might have proved the efficacy of drugs in that particular group and not universally irrespective of parity. However, to rule out the confounding effect of parity it was determined that all the three groups were matched for parity. In present study we observed an initial cervical dilatation to be lying in the range of 3 to $4 \mathrm{~cm}$. Previous studies by Barachio et al. and Davinder et al in literature have quoted similar findings (3$4 \mathrm{~cm}) .{ }^{18,19}$

In present study, both hyoscine butylbromide and drotaverine hydrochloride showed significant reduction in first stage of labour. As compared to placebo group both the groups had significantly lower mean duration of stage
I. Although the mean difference between placebo and Hyoscine butylbromide group for first stage of labour was 2:04 $\pm 0: 23 \mathrm{hr}:$ min whereas the difference between placebo

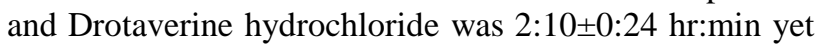
this mean difference of around 6 minutes did not differentiate between the two study groups. For total duration too similar pattern of difference was observed among the three groups. Thus as regards the duration of first stage as well as total duration of labour, both the study groups showed a significantly shorter time as compared to the placebo group. However, the difference between two study groups did not show a significant difference.

However, Tahelia et al observed the mean time from injection to full dilatation to be significantly lower in hyoscine butylbromide group as compared to Drotaverine hydrochloride group in both multipara and nullipara groups of their study. While, Gupta et al did not find a significant effect of either of two drugs on first stage of labour as well as total duration of labour. ${ }^{20}$

Although in different studies hyoscine butylbromide and drotaverine hydrochloride have independently been shown to be controversial. Chan et al did not find an impact of hyoscine butylbromide on the duration of first stage of labour whereas Sirohiwal et al have found that hyoscine $\mathrm{N}$-butyl bromide suppositories have a significant reducing effect on the first stage of labour. ${ }^{21,22}$ Samuels et al. too showed a similar reducing effect of hyoscine butylbromide on the mean duration of first stage of labour against a placebo. ${ }^{23}$ Raghavan et al in a comparative assessment of hyoscine butyl- bromide with valethamate bromide against a placebo showed a significantly better efficacy in both the test groups in acceleration of first stage of labour. ${ }^{24}$ Similarly for Drotaverine hydrochloride too Sharma et al, Khosla et al, Singh et al have shown a proven efficacy of drotaverine hydrochloride over placebo and other drugs. Roy et al reported it to be highly efficacious in reducing the duration of first stage of labour. Similar results have been reported in other studies too. ${ }^{25-29}$

Drotaverine hydrochloride is a highly potent spasmolytic agent, acting on the smooth muscle but is devoid of anticholinergic effects as it acts through inhibitory effect on phosphodiesterase enzyme, mainly PDE IV. Near term, human myometrium contains a higher proportion of rolipram sensitive type IV PDE isoforms. Drotaverine inhibits them and in turn increases the intracellular concentration of cAMP and cGMP and causes smooth muscle relaxation.

It does not cross the placenta and hence has no side effects on the fetus while hyoscine butylbromide is a quaternary derivative of atropine which acts as an anticholinesterase. It acts on the muscarinic receptors of the smooth muscles and competes for the receptor sites with acetylcholine. Being a quaternary ammonium derivative, it does not readily cross the blood brain barrier, so central effects, if any, are rare. Also, there are no known fetal effects of this compound. One of the reasons for variation in our results 
and that of those quoted in literature could be the varying bioavailability of drotaverine hydrochloride. However, considering the higher bioavailability and longer elimination half life of drotaverin hydrochloride as compared to hyoscine butylbromide, it might be considered to be a fast acting and more effective antispasmodic drug. But, the variation in results in three different studies with three different patterns needs a further exploration in order to ascertain the reasons which affect the bioavailability of drotaverine hydrochloride. The findings in present study show that both hyoscine butylbromide and drotaverine hydrochloride had a significant effect on the duration of first stage of labour as compared to control group. Though the incidence of side effects was slightly higher in drotaverine hydrochloride group as compared to hyoscine butylbromide group yet the two groups were comparable for all the outcomes. Thus, the present study finds both the drugs to be equally efficacious. However, as the varying efficiency is reported in different studies, the controversy still continues and needs further exploration in a larger study.

\section{CONCLUSION}

Both drotaverine hydrochloride and hyoscine butylbromide could effectively reduce first stage as well as total duration of labour. Further studies are recommended to establish the comparative efficacy in terms of a side effect profile and relatively efficacy in view of various clinico-demographic variables.

Funding: No funding sources Conflict of interest: None declared

Ethical approval: The study was approved by the Institutional Ethics Committee

\section{REFERENCES}

1. Boylan PC. Active management of labor: results in Dublin, Houston, London, New Brunswick, Singapore, and Valparaiso. Birth 1989;16:114-8.

2. O`Driscoll K, Stronge JM, Minogye M. Active management of labor. $\mathrm{J}$ Obstet Gynaec. 1970;77(5):385-9.

3. Bohra U, Donnelly J, O'Connell M, Geary M, Mac Quillian K, Keane DP. Active mangement of labour revisited: the first primiparous labours in 2000. J Obstet Gynaecol. 2003;23:118-20.

4. Singh KC, Jain P, Goel N, Saxena A. Drotaverine hydrochloride for augmentation of labour. Int $\mathrm{J}$ Gynaecol Obstet. 2004;84:17-22.

5. Hudecek R, Nagy J, Unzeeitig V. The effect of spasmolytics on dilatation of the uterine cervix. Ceska Gynaekol 1997;62:11-14.

6. Ahmad S, Rauf B, Shafiq A. Use of Spasfan in labour. J Himont Med. 2002;1:14-8.

7. Tehalia MK, Sajjan GR, Korbu J, Venkatesh S, Biradar R. A comparative study of hyoscine butylbromide versus drotaverine hydrochloride in first stage of labor. J Obstet Gynecol India. 2008;58(3):230-4.

8. Sadler LC, Davison T, Mccwan LM. A randomized controlled trial and meta-analysis of active management of labour. BJOG. 2000;107:909-15.

9. Sharma JB, Pundir P, Kumar A, Murthy NS. Drotaverine hydrochloride vs. valethamate bromide in acceleration of labor. Int $\mathrm{J}$ Gynaecol Obstet. 2001;74(3):255-60.

10. Impey L, Boylan P. Active management of labour revisited. Br J Obstet Gynaecol. 1999;106:183-7.

11. Pates JA, Satin AJ. Active management of labor. Obstet Gynecol Clin N Am. 2005;32:221-30.

12. Ritchie JW, Boyle DD. The active management of labour. Br J Hosp Med. 1980;26(1):61-5.

13. O'Herlihy C. Active management: a continuing benefit in nulliparous labor. Birth. 1993;20:95-7.

14. O’Driscoll K, Foley M, Macdonald D. Active management of labor as an alternative to cesarean section for dystocia. Obstet Gynecol. 1984;63:485-90.

15. Effect of hyoscine-N-butylbromide on duration of labour in term pregnancies in North Okkalapa General Hospital. Dissertation for Master of Medical Sc. (Obs. Gyn.), University of Medicine, Yangon, Burma, 2010. Available at http://www.authorstream.com/Presentation/Kyarphy u-448149-dissertation-presentation/. Accessed on 12 December 2016.

16. Sujatha V. Comparision of buscopan and epidosin on cervical dialatation in labour. Global J Med Res. 2010;10(2):18-21.

17. Ajmera SK, Shah PK, Shinde GA. Comparative Study of drotaverine $\mathrm{v} / \mathrm{s}$ valethamate in cervical phase of labour. Bombay Hospital Journal. 2006;48(2):305-9.

18. Barachio HM, Kamath J, Kunkalekar K, Jacob C. Hyoscine N-butyl bromide in acceleration of labour. $\mathrm{J}$ Obstet Gynaecol Ind. 1984;34(3):510-3.

19. Davinder K, Ravinder K. Comparison of drotaverine and episodin in first stage of labour. J Obstet Gynaecol Ind. 2003;53(4):449-52.

20. Gupta B, Nellor V, Mittal S. Drotaverine hydrochloride versus hyoscine-N-butylbromide in augmentation of labor. Int $\mathrm{J}$ Gyn Obs. 2008;100(3):244-7.

21. Chan DPC. The use of buscopan during the first stage of labour. The Bulletin of the Hong Kong Chinese Medical Association. 1963;15:69-71.

22. Sirohiwal D, Dahiya K, De M. Efficacy of hyoscineN-butyl bromide (Buscopan) suppositories as a cervical spasmolytic agent in labour. Aust NZJ Obstet Gynaecol. 2005;45(2):128-9.

23. Samuels LA, Christie L, Roberts GB, Fletcher H, Frederick J. The effect of hyoscine butylbromide on the first stage of labour in term pregnancies. BJOG. 2007;114(12):1542-6.

24. Raghavan R. The effect of hyoscine butyl bromide on the first stage of labour in term pregnancies. BJOG. 2008;115(8):1064.

25. Khosla AH, Bala I, Dahiya K, Sangwan K. Comparative study of the efficacy of valethamate 
bromide with drotaverine in normal labour. J Obst Gynaecol India. 2003;53(6):568-70.

26. Singh KC, Jain P, Goel N, Saxena A. Drotaverine hydrochloride for augmentation of labor. Int $\mathbf{J}$ Gynaecol Obstet. 2004; 84(1): 17-22.

27. Roy A, Patra KK, Mukhopadhyay S, Guha S. Study of drotaverine on first stage of labour and pregnancy outcome. J Indian Med Assoc. 2007;105(8):450-2.

28. Thapa M, Saha R, Pradhan A, Shrestha S. Effectiveness of drotaverine hydrochloride in progression of labour. NJ Obstet Gynaecol. 2007;2(2):9-11.
29. Madhu C, Mahavarkar S, Bhave S. A randomised controlled study comparing drotaverine hydrochloride and valethamate bromide in the augmentation of labour. Arch Gyn Obs. 2010;282(1):11-5.

Cite this article as: Kausar U, Siddiqui N. To compare the efficacy of drotaverine hydrochloride with hyoscine butylbroumide for increasing the rate of cervical dilatation.Int J Reprod Contracept Obstet Gynecol 2017;6:1614-20. 